\title{
Análise da Sustentabilidade do Regime Próprio da Previdência Social para assegurar a Aposentadoria. Município de Bandeira Minas Gerais
}

\author{
Maria Aparecida Alves Prates ${ }^{1}$; Graciela Fanego de Bianchi ${ }^{2}$
}

Resumo: Este estudo propôs um análise sobre a sustentabilidade do Regime Próprio de Previdência Social (RPPS) do município de Bandeira, Minas Gerais. Teve como objetivo o de coletar respostas para resolver o problema, qual seja, a análise da sustentabilidade do Regime Próprio de Previdência Social para assegurar a aposentadoria no Município de Bandeira, Minas Gerais, nos documentos pesquisados. A metodologia constou de pesquisa feita através de perguntas e respostas à gestora do Instituto Municipal PREVBAND, por meio eletrônico, e de outros dados disponíveis na internet. Os resultados demonstraram que a sustentabilidade do RPPS, no Município de Bandeira, por ser de pequeno porte, é possível no curto prazo, tendo em vista que há equilíbrio financeiro, verificado da análise da diferença entre a receita e despesa. Entretanto, em longo prazo, é necessária uma avaliação anual, atuarial criteriosa, ante o aumento gradativo das despesas previdenciárias e do prolongamento da expectativa de vida da população. Outros fenômenos econômicos e políticos, podem tornar insustentável, não só para o RPPS do município de Bandeira, mas para todos os Regimes Próprios de Previdência Social do Brasil.

Palavras chaves: Previdência Social, Regime Próprio de Previdência Social, Sustentabilidade, Responsabilidade Social e Controle.

\section{Analysis of the Sustainability of the Social Security System to ensure Retirement in the Municipality of Bandeiras in Minas Gerais}

\begin{abstract}
This study proposed an analysis on the sustainability of the Social Security System (RPPS) of the municipality of Bandeira, Minas Gerais. The objective was to collect answers to solve the problem, that is, the analysis of the sustainability of the Social Security System to ensure retirement in the Municipality of Bandeira, Minas Gerais, in the documents surveyed. The methodology consisted of research done through questions and answers to the manager of the Municipal Institute PREVBAND, through electronic, and other data available on the internet. The results showed that the sustainability of RPPS, in the Municipality of Bandeira, being small, is possible in the short term, considering that there is financial balance, verified from the analysis of the difference between revenue and expenditure. However, in the long term, a careful, annual actuarial evaluation is necessary, given the gradual increase in social security expenditures and the prolongation of life expectancy of the population. Other economic and political phenomena may make it unsustainable, not only for the RPPS of the municipality of Bandeira, but for all of Brazil's own Social Security Regimes.
\end{abstract}

Keywords: Social Security, Social Responsibility and Control.

\footnotetext{
${ }^{1}$ Mestrado em Maestría en Gobierno y Gerencia Pública pelo Universidad Americana del Paraguay, Paraguai (2016). Técnico em contas, Classe 'c' Nível "49" do Tribunal de Contas do Estado de Alagoas , Brasil;

${ }^{2}$ Universidad Americana. Facultad de Posgrado. Asuncion - Paraguay.
} 


\section{Introdução}

Os Regimes Próprios de Previdência Social dos Servidores Público são instrumentos constitucionais que visam assegurar, através de recursos financeiros, o bem estar do assegurado e de seus dependentes em razão do afastamento obrigatório da sua atividade laboral, seja por doença, invalidez ou idade avançada.

A Previdência Social no Brasil não deve ser analisada apenas, à partir dos aspectos orçamentários, financeiros e atuariais, pois isto significaria relegar a sua importante dimensão no aspecto social; bem como a primordial importância na eficácia de desenvolvimento de políticas públicas. É neste contexto em que se dá a análise da sustentabilidade do Fundo Previdenciário do Munícipio de Bandeira, localizado no Estado de Minas Gerais/Brasil, patrocinado pelo Regime Próprio da Previdência Social, para assegurar a aposentadoria dos servidores naquela localidade.

No atual cenário de crise no Brasil, a continuidade dessa política previdenciária configura-se comprometida, tendo em vista que o ritmo de crescimento das despesas públicas ligadas às políticas sociais tornou-se muito mais rápido que o da produção nacional. Esse distanciamento entre crescimento econômico e crescimento social aconteceu em razão da produção nacional ter sofrido grande redução, enquanto as despesas públicas sociais continuaram no seu crescimento natural. Esta pesquisa sobre o tema, além de estar ligada à questão social, também envolve o aspecto financeiro e atuarial do Regime Próprio de Previdência Social.

A sustentabilidade dos Regimes Próprios de Previdência Social refere-se à sua continuidade/perenidade e a sua possibilidade de pagamento dos benefícios previdenciários ao longo prazo, com a manutenção da qualidade de vida do segurado quando da sua aposentação. O sistema previdenciário, após a promulgação da Constituição e suas reformas, foi reformulado radicalmente diante dos antigos paradigmas relacionados à previdência social.

A Lei Complementar $\mathrm{n}^{\circ} 101$, de 04/05/2000, a Lei de Responsabilidade Fiscal, estabelece novidades sobre finanças públicas que merecerem especial atenção dos gestores públicos municipais, especialmente quando prevê que o ente da Federação que mantiver ou vier a instituir Regime Próprio da Previdência Social, deverá conferir-lhe caráter contributivo e organizá-lo com base em normas de contabilidade e atuária que preservem seu equilíbrio financeiro e atuarial.

Através da coleta de dados disponíveis na Internet e de análise de auditoria de fundos previdenciários no decorrer da carreira profissional, buscou-se obter um diagnóstico da situação financeira e atuarial do município pesquisado, além de avaliar aspectos, como a visão do gestor público diante da questão previdenciária municipal. 
Vale o esclarecimento que, no Brasil, os servidores públicos federais, estaduais e municipais não estão vinculados ao mesmo regime de previdência, ou seja, cada um tem o seu regime próprio, com fundos previdenciários separados para cada Ente.

Importante mencionar que há na Constituição Federal de 1988 a previsão da compensação financeira entre os regimes de previdência social. Trata-se de grande avanço para a sustentabilidade dos regimes previdenciários, pois, antes da promulgação da Carta de 1988, como não havia a previsão de compensação financeira cada regime previdenciário assumia o custo integral dos benefícios previdenciários concedidos, independentemente do tempo de contribuição feita, anteriormente pelo segurado para outros regimes previdenciários.

Estudos apontam que a falta de cálculos atuariais do Ente Municipal para o pagamento dos benefícios previdenciários ao longo prazo, sobretudo os de pequeno porte, causa insegurança no segurado e no próprio município, o que pode vir a afetar significativamente a economia e a estabilidade social. Demonstra-se, assim, um desafio ao gestor público, qual seja, atender a legislação vigente para o equilíbrio fiscal do orçamento, ao mesmo tempo em que não se pode descuidar da política de proteção social, cujo resultado será o gozo com segurança de recebimento pelo servidor de sua aposentadoria. No momento em que se enfatiza a busca pelo equilíbrio e sustentabilidade fiscal do orçamento municipal, faz-se necessária uma análise, que enfoque, também, a importância da manutenção de políticas de proteção social, voltadas, no caso específico, aos servidores públicos municipais. Como se vê, a magnitude do assunto é inquestionável, pois envolve, além do aspecto econômico, o social. Diante do exposto, nos indagamos: Qual é a análise da sustentabilidade do Regime Próprio de Previdência Social para assegurar a Aposentadoria no Município Bandeira Minas Gerais?

O Objetivo Geral deste trabalho consiste em determinar qual é a análise da sustentabilidade do Regime Próprio da Previdência Social para assegurar a aposentadoria do Município de Bandeira Minas Gerais. Para isso foram necessários também: a) Estabelecer se o Regime Próprio da Previdência Social é capaz de se sustentar e contribuir para assegurar a aposentadoria e a estabilidade social do município; b) Precisar se o Regime Próprio da Previdência Social do município é capaz de se sustentar e contribuir para o equilíbrio fiscal; c) Analisar se diante de um cenário de crise, marcado pela perda do poder aquisitivo dos salários e pelo rígido controle dos gastos públicos, seria possível manter o equilíbrio financeiro e atuarial do Regime Próprio de Previdência Social e ter responsabilidade social com aposentadoria, conforme preconizado na legislação vigente e, d) Avaliar a forma como o gestor público encara a questão previdenciária no seu município 


\section{Regime Próprio da Previdência Social e a Sustentabilidade}

Sustentabilidade: é a palavra usada para definir ações que visam suprir as necessidades atuais e garantindo o futuro das próximas gerações. Na área previdenciária, a sustentabilidade é um princípio jurídico que determina o desenvolvimento social nos aspectos materiais e imateriais, de modo inclusivo, durável e com igualdade, das atuais e futuras gerações (DIAS, 2012).

Trazida para o aspecto previdenciário, a sustentabilidade dos RPPS acontece quando existe o equilíbrio financeiro atuarial, combinados com as políticas públicas. Ademais, a sustentabilidade referese à continuidade/perenidade dos regimes e dos respectivos planos de benefícios e a possibilidade de pagamento dos benefícios previdenciários no longo prazo, assegurando a manutenção da qualidade de vida do segurado quando da sua aposentação.

\section{RPPS: da Seguridade social à Aposentadoria}

A garantia à seguridade social relacionada aos Regimes Próprios da Previdência Social (RPPS), direito decorrente do trabalho, vinculado a uma contribuição mensal e prévia, tendo como beneficiários os segurados e seus dependentes. Seu fundamento é que todo cidadão tem direito a uma renda no momento em que sua capacidade para o trabalho diminui, desta forma, a garantia de uma aposentadoria apresenta relação com o conceito de cidadania.

Segundo ALMEIDA, D C (2012), a proteção social do trabalhador contra os infortúnios evoluiu na história constitucional brasileira a partir de um sistema de natureza assistencial, sem obrigatoriedade de contribuição social, cuja normativa data da Constituição de 1891, até um regime tipicamente previdenciário, em que a concessão de benefícios decorre de filiação obrigatória, baseada na investidura em cargo público efetivo e de pagamento de contribuição.

O histórico da aposentadoria do servidor público foi prevista, pela primeira vez, na Constituição da República dos Estados Unidos do Brasil de 1891, no art. 75, que assim definiu: “A aposentadoria só poderá ser dada aos funcionários públicos em caso de invalidez no serviço da Nação". (BRASIL, 1891).

\section{Os Regimes Próprios da Previdência Social dos Municípios}

Observa-se que no município onde não existe um regime próprio de previdência, os seus servidores ficam vinculados ao RGPS, como se fossem empregados, e o município passa a ser 
considerado, para fins previdenciários, como empresa, com todas as obrigações com os servidores exigidos por esse regime.

Desta forma, as vantagens, quando da implantação dos RPPS Municipais, é da redução de custos para o ente federativo em relação ao vínculo que eles têm com INSS. Portanto, instituir um Regime Próprio de Previdência nos municípios pode gerar economia de recursos previdenciários. Para isso, o município tem que estar atento com a capacitação dos seus servidores para melhor eficiência da gestão previdenciária. Isso porque, ao implantar um RPPS, este passa a ser fiscalizado pelo Ministério de Previdência Social. A partir daí, existem uma série de requisitos e normas para ser seguidas para dar continuidade ao regime. Isso demonstra que não é só criar, tem que existir a responsabilidade e a consciência previdenciária de saber que não pode usar livremente os recursos previdenciários do ente federativo.

\section{A Administração e Organização dos RPPS Municipais}

O RPPS Municipal é um regime previsto pela Constituição federal de 1988, especialmente para os servidores efetivos estatutários, instituído por lei do ente federativo. A sua criação fez aumentar as responsabilidades administrativas dos municípios, pois, além de promover a arrecadação da contribuição, o ente municipal deverá definir sua unidade gestora, bem como a forma pela qual será administrado o regime.

Em geral, estão sendo criados os RPPS de duas formas: a) Através de um fundo integrado de bens, conforme o disposto do artigo $6^{\circ}$ da Lei 9.717/98; b) Ou podendo ser um órgão, autarquia, fundação, com independência financeira e administrativa.

A taxa de administração é o fator que limita os gastos dos valores arrecadados dos recursos previdenciários e ela deve ser utilizada para custear o funcionamento da unidade gestora do RPPS.O percentual da taxa está estabelecido no artigo 41 da orientação normativa de 02/2009, da Secretaria da Previdência Social:

\footnotetext{
“ARTIGO 41. Para cobertura das despesas do RPPS com utilização dos recursos previdenciários, poderá ser estabelecida, em lei, taxa de administração de até dois pontos percentuais do valor (2\%) total das remunerações, proventos e pensões dos segurados vinculados ao RPPS, relativo ao exercício financeiro anterior".
} 


\section{Pontos Positivos dos RPPS Para o Município}

Economia com Alíquotas: No Regime Próprio de Previdência Social as alíquotas podem variar entre $11 \%$ e $22 \%$, de acordo com a avaliação atuarial realizada anualmente, enquanto que no Regime Geral de Previdência Social as alíquotas de contribuição são fixadas em $22 \%$ e aplicadas sobre a folha de pagamento. Isso significa uma economia possível de até 50\% com encargos previdenciários. Gerase, assim, uma considerável economia ao erário público e dando a possibilidade dos mesmos utilizarem estes recursos economizados em outras áreas, sendo algo bastante atrativo para os gestores dos entes federados municipais.

Controle administrativo: No RGPS/INSS os benefícios são concedidos à revelia da administração, pois, normalmente, é a última a ser informada que o funcionário foi aposentado. Já no RPPS, a administração tem controle total da concessão dos benefícios e pode programar para substituir o servidor que adquire direito a aposentadoria.

Limite de Gasto com pessoal (LRF): os encargos previdenciários integram o cálculo do limite de gasto com pessoal previsto pela Lei de Responsabilidade Fiscal. Implantando o RPPS o município tem uma queda considerável com seus encargos e melhora seu índice com o gasto com pessoal.

Compensação financeira: Implantando o RPPS, o município passa a ser credor do INSS, podendo realizar a compensação financeira previdenciária, buscando recursos no INSS/RGPS e capitalizando cada vez mais seu RPPS. Além do mais os servidores públicos que integravam o RGPS, quando passam a integrar o RPPS podem reaver suas contribuições, possibilitando mais ainda um bom equilíbrio financeiro, passando os entes a receberem do INSS e não mais pagarem a ele, como afirma Schramm (2011). "Os municípios ao criarem os RPPS passam a se tornarem credores do INSS, tendo em vista que os valores são recuperados em forma de compensação."

Economia com base de cálculo: No INSS/RGPS a base de cálculo patronal incide sobre todas as verbas da folha de pagamento. No RPPS a base de cálculo patronal incide somente sobre as verbas permanentes e incorporáveis. Essa diferença na base de cálculo pode representar uma economia expressiva.

Superávit na criação: No momento em que é criado o RPPS certamente se tem um superávit, pois existe mais ativos contribuindo do que inativos, gerando assim uma margem de reserva e esta quantia pode ser investida como forma de capitalização dos recursos, gerando assim um maior rendimento do capital do regime, garantindo uma maior capacidade financeira para o futuro dos seus contribuintes.

Recursos financeiros: No INSS/RGPS os recursos das contribuições previdenciárias vão para o Governo Federal. No RPPS as contribuições são controladas pela própria unidade gestora do RPPS e investidas no mercado financeiro através das agências bancárias do próprio município. Muitas 
prefeituras conseguem atrair novos bancos para abrir agências em seus municípios por conta dos recursos que seus RPPS têm para investir e movimentar. Isso favorece a geração de empregos e a economia local.

Regime jurídico celetista: os municípios que ainda tem o regime celetista como regime jurídico único para os servidores de cargo efetivo são obrigados a arcar com uma despesa adicional de $8 \%$ referente ao FGTS e são filiados obrigatoriamente ao INSS. Antes de implantar seu RPPS, esses municípios devem alterar o regime jurídico desses servidores, passando-os para o regime estatutário. Isso representará uma economia imediata de $8 \%$, visto que o servidor estatutário não tem direito ao FGTS.

Pode ser uma alternativa: Os RPPS que passam por boas gestões, com administradores que tenham uma visão em longo prazo, investindo o capital ocioso em rendimentos de baixo risco e boa lucratividade. E também outra maneira de ter segurança é a realização com frequência de um estudo atuarial para que assim possam saber de quanto deve ser arrecado dos contribuintes para que futuramente o regime não venha ser deficitário, associado a um controle externo eficaz. Desta forma, os RPPS podem ser vistos como uma boa alternativa para o sistema previdenciário brasileiro.

\section{Outras vantagens para o Município}

Maior transparência; Maior facilidade de fiscalização; Participação dos servidores nos conselhos, auxiliando o Município na administração do Regime Próprio de Previdência Social. (Inciso IV do Artigo $1^{\circ}$ da Lei n 9.717 , de 1998); Maior economia; Redução de ações judiciais.

\section{Pontos Positivos para o Servidor do RPPS}

- Maior agilidade na concessão de benefícios, ausência de carência;

- Possibilidade de Paridade e Integridade, para os benefícios concedidos para quem ingressou até a data da EC 41/03; (Art.6 $6^{\circ}$ da Emenda Constitucional n ${ }^{\circ} 41$, de 2003 e $3^{\circ}$ da Emenda Constitucional $n^{\circ} 47$ de 2005);

- Não aplicação do teto de benefícios do RGPS;

- Não incidência de carência ou prazo de espera para a obtenção da aposentadoria compulsória;

- Participação do servidor, ativo, inativo, pensionistas, na gestão do RPPS por meio dos conselhos administrativo e fiscal;

- Regras de benefícios diferentes das estabelecidas para o RGPS; 
- Abono de Permanência pago aos servidores que preencherem os requisitos e critérios para aposentadoria, permanecendo no serviço, exceto os amparados pelo disposto no artigo $3^{\circ}$ da Emenda Constitucional n 47/2005;

- Não incidência no cálculo dos benefícios de aposentadoria do fator previdenciário;

- Fiscalização mediante o Tribunal de Contas do Estado, servidor e Ministério da Previdência Social.

\section{Problemas que podem ocorrer nos RPPS Municipais}

Os Regimes Próprios de Previdência Social (RPPS), presentes no artigo 40 da Constituição Federal de 1988, fortalecidos pelas emendas constitucionais n. 20 e n. 41 e regulamentados pela Lei 9.717/98, apareceram como uma forma de aliviar o Regime Geral de Previdência Social (RGPS) que passava e continua a passar por grande déficit financeiro, decorridos por vários fatores como fraudes e má administração. Devido a isso, os gestores públicos dos entes federativos na sua maioria passaram a ver os RPPS com uma forma atrativa tanto pelas vantagens que seriam dadas para o município, como também para o servidor público.

Estes gestores que decidiram implantar os RPPS nos seus municípios tiveram como ideia apenas a fonte de arrecadação e que haveria uma diminuição de despesas e obtenção de receitas no curto prazo, haja vista que, no início, o ente só iria arrecadar com as contribuições dos integrantes do regime e da parcela patronal. Entretanto, caso estes recursos não sejam devidamente investidos em tipos de capitalização seguras, como, por exemplo, títulos de capitalização do governo, esses regimes ao longo do tempo certamente vão se tornar deficitários, levando em conta o crescimento de beneficiários em comparação ao número de contribuintes.

Outra situação para se observar seria a aplicação dos recursos dos RPPS em investimentos com grau de risco elevado, podendo os recursos ser aplicados até $30 \%$ em bancos, empresas ou outrem. Entretanto, deve-se ressaltar que muitas dessas aplicações nessas instituições de alto risco podem causar prejuízo, dando assim uma perda nos recursos que foram investidos pelo regime, o que é algo alarmante, pois geraria um grande desfalque ao RPPS, podendo leva-lo a uma crise financeira sem recuperação.

Outro fator que chama a atenção nos RPPS é a fiscalização desses regimes que são auditados por órgãos públicos, como o Tribunal de Contas, como também por parte integrante da sociedade, através de conselhos. Entretanto, o que se observa é que, na prática, o chefe do Poder Executivo por deter a possibilidade de indicação de cargos comissionados de livre nomeação para gestão dos fundos e também pela maioria dos integrantes dos conselhos pertencerem ao Poder Executivo, acaba deixando 
os RPPS sem autonomia e liberdade de ação nas tomadas de decisões, já que cabe apenas a uma minoria representar a sociedade de forma mais imparcial.

Quando o regime passa a ser deficitário, surgem os problemas relacionados à sua sustentabilidade. Quando o regime próprio passa a ser deficitário, sem condição de arcar com o passivo financeiro, ele pode ir à falência e levar os contribuintes, aposentados e pensionistas a uma situação previdenciária descoberta, pois, para que os integrantes dos RPPS voltem a fazer parte do RGPS, será necessário que município repasse todos aqueles recursos recebidos de contribuição do servidor e do ente federado durante esses anos, o que certamente é inviável, tendo em vista que se os RPPS não tem condição financeira de arcar com o pagamento atual de seus beneficiários, imagina quanto às contribuições ao longo dos anos. A situação do servidor é de fragilidade e de insegurança futura.

\section{Problemas oriundos de má gestão dos RPPS}

Falta de levantamento atuarial com frequência; Falta de parecer atuarial anual na prestação de contas; Falta de certificado de regularidade previdenciária; Gestores com pensamento em curto prazo, que não investem de maneira correta, no momento em que o regime possui uma boa margem financeira; Desvios de recursos para fins que não sejam previdenciários; Fraudes previdenciárias.

\section{Panorama dos RPPS dos Municípios de Minas Gerais}

A previdência social é parte integrante do sistema de proteção social instituído no Brasil, sendo que o trabalhador em idade ativa sacrifica parte de sua renda presente, mediante contribuição compulsória, para que na inatividade e/ou invalidez ou morte, possa receber os benefícios que lhe são devidos.

Com a Constituição Federal de 1988, um grande número de municípios brasileiros acabou adotando Regimes Jurídicos Únicos, com o objetivo principal de desvincular os seus servidores do RGPS, administrado pelo INSS, ligando-os aos RPPS criados em seus municípios. É notório que as leis orgânicas municipais copiaram e ampliaram as vantagens e benefícios de seus servidores, tanto os já contidos na Lei ${ }^{\circ}$ 8.112/90, onerando cada vez mais os recém-criados regimes previdenciários.

A maioria dos RPPS municipais que surgiram a partir de 1992, no estado de Minas Gerais, tal como ocorreu nos demais estados brasileiros, também não difere dos outros estados, com relação ao modelo adotado de proteção social baseado na contribuição, em que os benefícios são condicionados às contribuições passadas e à afiliação compulsória dos indivíduos. 
Nos municípios mineiros, esses regimes foram criados e instituídos para garantir os benefícios aos servidores públicos municipais, mediante contribuição dos servidores e do município. A preservação do equilíbrio atuarial e financeiro constitui questão de destaque ao tratar de direitos previdenciários, pois a visão de longo prazo deverá sobrepor-se à visão de curto prazo, porque um sistema de previdência normalmente produz seus maiores impactos no médio e longo prazo.

Há que se destacar que a avaliação atuarial mostra fundamental importância em se tratando da sustentabilidade dos RPPS. Outro ponto que merece ser destacado na análise da situação dos RPPS municipais é o Certificado de Regularidade Previdenciária (CRP). Vale salientar que o ente federativo deve prestar ao MPS e ao auditor da previdência, todas as informações solicitadas sobre o RPPS, podendo este auditor ter o livre acesso a todos os registros e documentos para que possa analisar e atestar o cumprimento da legislação que disciplina a gestão do Regime Próprio da Previdência Social.

O marco institucional dos RPPS foi a Emenda Constitucional 20/1998 e depois a Emenda Constitucional 41/2003, ambas tiveram por objetivo garantir a sustentabilidade do sistema previdenciário. Entretanto, apesar das reformas citadas, ainda hoje, a grande parte dos RPPS dos entes da federação apresentam em sua maioria expressivos déficits atuariais.

\section{Aspectos Principais e Análises dos Municípios Mineiros}

Minas Gerais é o estado brasileiro com maior número de municípios, somando 853 no total, segundo informações obtidas no sítio eletrônico da Wikipédia, 2016.

O foco do trabalho é um dos municípios localizados em Minas Gerais que irá tratar da análise da sustentabilidade do Regime Próprio de Previdência Social para assegurar a aposentadoria, na cidade de Bandeira, Minas Gerais. O município de Bandeira, tomado como pesquisa no presente trabalho, está encravado no Vale do Jequitinhonha, nordeste do estado de Minas Gerais, e é uma cidade de pequeno porte.

\section{Distribuição dos Regimes Previdenciários em Minas Gerais}

No Estado de Minas Gerais existem 212 municípios que possuem RPPS. A tabela abaixo apresenta a distribuição dos regimes previdenciários existentes em todo o Estado: 
Regimes previdenciários de Minas Gerais

\begin{tabular}{|c|c|c|}
\hline REGIMES & MUNICÍPIOS & PERCENTUAIS \% \\
\hline RGPS & 604 & $70,81 \%$ \\
\hline RPPS & 212 & $24,85 \%$ \\
\hline RPPS EM EXTINÇÃO & 37 & $4,34 \%$ \\
\hline TOTAL & 853 & $100 \%$ \\
\hline
\end{tabular}

Elaboração Própria - Dados- Posição em 19/08/2014-MPS- Ministério da previdência Social

\section{Municípios Com e Sem Certificado de Regularidade Previdenciária}

O Certificado de Regularidade Previdenciária - CRP é um documento fornecido pela Secretaria de Políticas de Previdência Social - SPS, do Ministério da Previdência Social, que atesta pelose os regimes próprios de previdência social de um Estado, do Distrito Federal ou de um Município estão cumprindo os critérios e exigências estabelecidos na Lei $n^{\circ}$ 9.717/98. Desta forma, o certificado atesta que o ente federativo segue as normas de boa gestão, de forma a assegurar o pagamento dos benefícios previdenciários aos seus segurados, e também o regular repasse de contribuições e o devido parcelamento dos débitos dos entes federativos. Trata-se de documento fundamental para assegurar o pagamento dos benefícios aos segurados.

Na ausência do CRP, Estados e Municípios ficam impedidos de:

- Receber recursos de transferências voluntárias da União;

- Realizar financiamentos;

- Iniciar empréstimos por instituições financeiras federais e internacionais;

- Recolher repasses da compensação previdenciária pelo Instituto Nacional do Seguro Social (INSS);

- Celebrar acordos, contratos, convênios ou ajustes com a União.

Importante mencionar que o CRP não será exigido nos casos de transferências relativas às ações de educação, saúde e assistência social.

A portaria do MPS n ${ }^{\circ}$ 204/2008 determina que a pessoa responsável pela realização de qualquer ato que exige CRP deverá juntar, ao processo ou atestar nos autos, a verificação de sua validade mencionando o seu número e data de emissão. 
Municípios Com e Sem Certificado Regularidade Previdenciária:

\begin{tabular}{|c|c|c|}
\hline CERTIFICADO & MUNICÍPIOS & PERCENTUAIS \% \\
REGULARIDADE & & \\
PREVIDENCIÁRIA & 114 & $53,77 \%$ \\
\hline COM CERTIFICADO & & \\
REGULARIDADE & 98 & $46,23 \%$ \\
PREVIDENCIÁRIA-CRP & & \\
\hline $\begin{array}{c}\text { SEM CERTIFICADO } \\
\text { REGULARIDADE }\end{array}$ & 212 & $100 \%$ \\
\hline PREVIDENCIÁRIA-CRP & & \\
\hline TOTAL & & \\
\hline
\end{tabular}

Elaboração Própria - Dados- Posição em 19/08/2014-MPS- Ministério da previdência Social

\section{Aplicação dos Recursos dos RPPS dos Municípios de Minas Gerais.}

A aplicação dos recursos dos Regimes Próprios de Previdência Social, conforme o disposto no artigo $1^{\circ}$ da Lei 9.717/98, que devem seguir as disposições relacionadas às condições de segurança, rentabilidade, solvência, liquidez e transparência. Os recursos previdenciários aplicados dos RPPS foram regulamentados pelas Resoluções CMN n 2.652/1999, com vigência de 24/09/99 a 31/10/04, nº 3.244/04, com vigência de 01/11/04 a 29/10/07, no 3.506/07, com vigência de 30/10/07 a 27/09/09, n o 3.790/09, com vigência de 28/09/09 a 28/11/10, e no 3.922/10, em vigência desde 29/11/10.

\section{Aplicação dos Recursos dos RPPS/MG}

\begin{tabular}{|l|r|r|}
\hline \multicolumn{1}{|c|}{ SEGMENTO } & \multicolumn{1}{c|}{ VALOR } & \% \\
\hline Renda Fixa & $4.233 .596 .075,59$ & $92,03 \%$ \\
\hline Renda Variável & $338.589 .300,80$ & $7,36 \%$ \\
\hline Disponibilidades Financeiras & $15.061 .519,92$ & $0,33 \%$ \\
\hline Ativos em Enquadramento & $7.943 .400,79$ & 0,17 \\
\hline Demais bens, direitos e ativos. & $4.848 .999,11$ & 0,11 \\
\hline Total & $4.600 .039 .296,21$ & $100,00 \%$ \\
\hline
\end{tabular}

Elaboração Própria - Dados Mps-Demonstrativos das Aplicações e Investimentos dos Recursos Dair/1ºbimi/2014

\section{Resultado Atuarial dos RPPS Municipalsem Segregação}

A avaliação atuarial é uma visão de longo prazo, um estudo técnico no qual o atuário mensura os recursos (patrimônio) necessários para a cobertura dos benefícios oferecidos pelo Plano de Benefícios. A avaliação atuarial é elaborada a partir de dados estatísticos da população coberta pelo Plano, como a taxa de mortalidade, taxa de sobrevida após a aposentadoria, taxa de invalidez por doenças 
e por acidentes, taxa de retorno esperada para os investimentos, entre outras. É o Demonstrativo de Resultado da Avaliação Atuarial - DRAA que descreve detalhadamente a massa de dados utilizados na avaliação, projeções atuariais detalhadas do fluxo de receitas e despesas e uma análise de sensibilidade, apresentando os resultados atuariais considerando a variação das principais premissas e hipóteses utilizadas.

A portaria MPS n 403/2008 no artigo $2^{\circ}$ dispõe de uma série de definições, iniciando por conceituar o equilíbrio atuarial:

"Equilíbrio atuarial, garantia de equivalência, a valor presente, entre o fluxo das receitas estimadas e das obrigações projetadas, apuradas atuarialmente, ao longo prazo."

Para o município verificar as vantagens ou desvantagens para criação de um RPPS faz-se necessária uma avaliação atuarial e também um planejamento com relação ao plano de custeio e do plano de benefícios. O plano de custeio envolve o estudo matemático financeiro para apurar o planejamento dos valores a serem arrecadados em relação ao grupo de servidores do município e apurar os percentuais das alíquotas de contribuição patronal e dos servidores para implantação de um RPPS. É por meio da atuária que muitos autores definem o equilíbrio financeiro para tornar viável o sistema previdenciário, por esse princípio, o ente previdenciário não pode gastar mais do que arrecada. A sobra tem que ser destinada para constituir uma reserva financeira para o futuro.

O Princípio atuarial pretende direcionar o Sistema Previdenciário em sua gestão, para que sempre seja viável a sua manutenção e sustentabilidade e é de suma importância, tanto que foi elevado ao nível constitucional.

Há uma tendência de se pensar que o cálculo atuarial, especialmente o déficit apurado, trata-se de um compromisso hipotético, pois depende de um grande número de fatores incertos e por um longo período. Outra linha de defesa dos administradores municipais é que as premissas dos atuários não se concretizarão. Apesar da ideia de ser hipotético, não se pode descartar a possibilidade, de forma que o Estado não pode arranjar justificativas para não fazer os cálculos atuariais. Desta forma, o parecer de um profissional da área de atuária tem recomendações para que o regime possa suportar futuramente o sustento de pessoas quando não mais tiverem capacidade laboral. $\mathrm{O}$ parecer atuário está pautado na legislação previdenciária e prescrições da ciência. Ocorre que, muitas vezes, as advertências do atuário não são interessantes para os municípios, pois podem inviabilizar a execução de seus projetos, tendo um impacto relevante nas despesas da prefeitura, de forma a comprometer, inclusive, as novas eleições e projetos de poder que são os interesses maiores dos agentes políticos. 
Municípios de Minas Gerais - com Déficit Atuarial no RPPS:

\begin{tabular}{|l|c|}
\hline \multicolumn{1}{|c|}{ RPPS } & MUNICÍPIOS \\
\hline RPPS SEM SEGREGAÇÃO & 174 \\
\hline DÉFICIT ATUARIAL & R\$ 8,5 BILHÕES \\
\hline
\end{tabular}

Elaboração Própria - Dados MPS - Ministerio Previdencia Social. Demonstrativos - (DRAA 2013)

\section{Resultado Financeiro dos RPPSde Minas Gerais}

A situação financeira deficitária vivida pela maioria dos RPPS municipais tem levado a explicação para a insuficiência de caixa dos municípios, a qual estaria enforcando a capacidade de investimento em setores sociais básicos como saúde e educação. O sistema previdenciário é de grande importância, considerada como política pública, e nota-se que as suas parcelas, em alguns casos, são a única fonte de renda de muitos cidadãos. Além disso, os contribuintes, ao longo de sua vida profissional, contam com essa renda como seu suporte financeiro no futuro.

O Plano de Custeio são fontes de recursos necessárias para o financiamento dos benefícios oferecidos pelo Plano de Benefícios e taxa de administração, representadas pelas alíquotas de contribuições previdenciárias a serem pagas pelo ente federativo, pelos servidores ativos e inativos e pelos pensionistas ao respectivo RPPS e aportes necessários ao atingimento do equilíbrio financeiro e atuarial, com detalhamento do custo normal e suplementar.

Segundo Bispo, (2004),"sabe-se, no entanto, que a situação vivida pelos RPPS de um modo geral é de diagnóstico muito mais complexo do que o que se costuma divulgar. Atentar apenas para o simples confronto Receita x Despesa pode parecer suficiente. Mas não o é, definitivamente. É preciso incorporar outros elementos à análise, afinal de contas o contexto que encerra a questão da sustentabilidade dos RPPS é plenamente desfavorável ao equilíbrio financeiro e atuarial dos mesmos, conforme já foi visto. Não se pode perder de vista, por exemplo, que não houve uma capitalização dos recursos arrecadados no passado, posto que a lógica que regia a previdência do servidor público era outra, totalmente distinta da atual. Muito pelo contrário, os fundos foram invariavelmente mal geridos e os recursos aplicados em objetivos estranhos à previdência social. Resta saber, então, como comparar despesas e dívidas assumidas em época passada - cujas regras e conceitos eram bastante peculiares com receitas auferidas no presente, e que, portanto, não poderão ser capitalizadas por absoluta insuficiência de tempo de aplicação? Desse balanço de contas dificilmente resultará saldo positivo".

O equilíbrio financeiro consiste em depois de realizada a arrecadação e feitos os pagamentos, não haver saldo negativo nos fundos previdenciários, evitando danos às contas públicas. 
O equilíbrio financeiro reflete-se a existência de reservas monetárias ou de investimentos, numerário ou aplicações suficientes para ao cumprimento dos compromissos atuais e futuros previstos. Não se vislumbra apenas os direitos atuais, mas também os que futuramente irão se materializar. O tema, apesar de contar com mais de dez anos de existência, recebeu pouca atenção e como não há definição legal do que sejam os mencionados critérios que preservem o equilíbrio financeiro e atuarial fica de difícil análise a situação atual dos sistemas.

A portaria MPS no 403/2008 no artigo $2^{\circ}$ dispõe de uma série de definições, iniciando por conceituar o equilíbrio financeiro nos seguintes termos:

"Equilíbrio financeiro: garantia de equivalência, entre as receitas auferidas e as obrigações do RPPS em cada exercício financeiro". Portaria MPS n $403 / 2008$

Municípios de Minas Gerais - Resultado Financeiro:

\begin{tabular}{|c|c|c|c|}
\hline \multicolumn{2}{|c|}{ DIPR-FEV/2014 (179 ENTES) } & \multirow{2}{*}{$\begin{array}{l}\text { VALOR } \\
\end{array}$} & \multirow{2}{*}{$\%$} \\
\hline DE & APOSENTADOS & & \\
\hline CÁLCULO & PENSIONISTAS & $2.376 .394,39$ & $0,60 \%$ \\
\hline & TOTAL & $395.605 .053,52$ & $100 \%$ \\
\hline & CONTRIBUIÇÕES & $115.059 .777,42$ & $51,88 \%$ \\
\hline INGRESSOS & APORTES & $20.487 .161,69$ & $9,24 \%$ \\
\hline DE & PARCELAMENTO & $8.327 .950,55$ & $3,75 \%$ \\
\hline RECURSOS & $\begin{array}{l}\text { COMPENSAÇÃO } \\
\text { FINANCEIRA }\end{array}$ & $4.432 .199,34$ & $2,00 \%$ \\
\hline \multirow[t]{4}{*}{ RECEITA } & APLICAÇÕES & $71.473 .424,57$ & 32,22 \\
\hline & OUTROS & $2.016 .294,06$ & 0,91 \\
\hline & TOTAL & $221.796 .807,63$ & $100,00 \%$ \\
\hline & APOSENTADORIA & $84.540 .210,19$ & $70,98 \%$ \\
\hline UTILIZAÇÃO & PENSÃO POR MORTE & $15.176 .611,77$ & $12,74 \%$ \\
\hline DE & AUXÍLIO DOENÇA & $3.715 .809,12$ & $3,12 \%$ \\
\hline \multirow{2}{*}{ RECURSOS } & ÕUTROS BENEFÍCIOS & $1.057 .713,15$ & $0,89 \%$ \\
\hline & BENEFÍCIOSDO TESOURO & $10.242 .942,18$ & $8,60 \%$ \\
\hline \multirow[t]{3}{*}{ DESPESA } & DESPESAS ADMINTRATIVA & $3.762 .031,91$ & $3,16 \%$ \\
\hline & OUTRAS & $613.557,33$ & $0,52 \%$ \\
\hline & TOTAL & $\mathbf{1 1 9 . 1 0 8 . 8 9 5 , 6 5}$ & $100,00 \%$ \\
\hline RESULTADO & $\begin{array}{l}\text { TOTAIS INGRESSOS } \\
\text { RECEITA }\end{array}$ & $221.796 .807,63$ & $100 \%$ \\
\hline \multirow[t]{3}{*}{ FINANCEIRO } & $\begin{array}{l}\text { TOTAIS } \\
\text { DESPESA }\end{array}$ & $119.108 .895,65$ & $53,70 \%$ \\
\hline & RESULTADO & 102.687.911,98 & $46,30 \%$ \\
\hline & SERVIDORES & 188.799 & $83,49 \%$ \\
\hline \multirow[t]{3}{*}{ BENEFICIÁRIOS } & APOSENTADOS & 29.676 & $13,12 \%$ \\
\hline & PENSIONISTAS & 7,669 & $3,39 \%$ \\
\hline & TOTAIS & 226.144 & $100 \%$ \\
\hline
\end{tabular}

Elaboração Própria - Dados do MPS - Ministerio Previdencia Social-Demonstrativos-fev-2014 


\section{Análise do RPPS do Município de Bandeira Minas Gerais}

Bandeira é um município mineiro, localizado no Vale do Jequitinhonha. A extensão do município é de 483,789 $\mathrm{Km}^{2}$, e, de acordo, com o Censo de 2010 tem 4.987 habitantes. A economia do município se sustenta na pecuária e na agricultura familiar.

\section{Da Análise da Pesquisa}

A análise desenvolvida foi feita a partir do sítio eletrônico da Prefeitura do Bandeira, no seu Portal da Transparência, bem como através de relatórios e informações obtidosatravés da internet e por um questionário ao Instituto de Previdência- PREVBAND, respondidas pelo Gestor do Fundo, através do endereço virtual: prevband@ hotmail.com.

\section{Características do RPPS do Município de Bandeira, Minas Gerais.}

O Regime Próprio de Previdência Social foi criado em 2003, através de Lei Municipal n. 277, que regulamentou benefícios e garantias, no intuito de garantir:

- Meios de subsistência nos eventos de invalidez, doença, acidente em serviço, idade avançada, reclusão e morte;

- Proteção à maternidade e a família.

A referida lei municipal foi elaborada pelo então Chefe do Poder Executivo Municipal da época, Domingas de Almeida Carvalho, e publicada em 20 de maio de 2003.

Esse RPPS tem como segurados obrigatórios:

- O servidor público titular de cargo efetivo dos órgãos do Poder Executivo, suas autarquias, inclusive as de regime especial e fundações públicas.

- Os aposentados que se mantiverem sob a égide e vigência desta lei.

Com a Lei no 332/2008, o Regime Próprio de Previdência Social passa a ser gerido por uma Autarquia Municipal, denominada Instituto de Previdência Municipal de Bandeira-PREVBAND, que substituiu o Fundo Municipal de Previdência - FPM do Município de Bandeira, criado através da Lei Municipal 277/2003. 


\section{Do Plano de Custeio}

O PREVBAND, que tem como fonte de custeio, as seguintes receitas, conforme capítulo III, do artigo 12, da Lei n. 332/2008:

- Contribuição previdenciária dos instituidores;

- Contribuição previdenciária dos segurados ativos;

- Contribuição previdenciária dos segurados aposentados e dos pensionistas;

- Contribuição suplementar do Município;

- Doações, subvenções e legados;

- Receitas decorrentes de aplicações financeiras e receitas patrimoniais;

- Valores recebidos a título de compensação financeira, em razão do parágrafo $9^{\circ}$, do artigo 201 da Constituição Federal;

- Demais dotações previstas no orçamento municipal.

As receitas de que trata este artigo somente poderão ser utilizadas para o pagamento de benefícios previdenciários do PREVBAND e da taxa de administração destinada à manutenção do Regime.

A taxa de administração, a ser utilizada mensalmente na cobertura das despesas administrativas do regime próprio, será de até dois pontos percentuais $(02 \%)$ do valor da remuneração, proventos, pensões dos segurados vinculados ao PREVBAND, relativamente ao correspondente ao exercício financeiro anterior. As aplicações financeiras dos recursos citados atenderão às resoluções do Conselho Monetário Nacional, sendo vedada a aplicação em títulos públicos, exceto quando se tratar de títulos públicos federais.

As contribuições previdenciárias serão descontadas no percentual de $11 \%$ (onze por cento) da remuneração dos servidores. Ademais, ainda há uma contribuição suplementar que é paga pelo o município no percentual de $4 \%$ (quatro por cento),e só será utilizada quando existir déficit atuarial decorrente dos serviços passados não contribuídos.

O município é o responsável pela cobertura de eventuais insuficiências financeiras do PREVBAND.

O plano de custeio do PREVBAND deve ser revisto, anualmente, sendo necessárias que sejam observadas as normas gerais de atuária, para que se mantenha o seu equilíbrio financeiro e atuarial. $\mathrm{O}$ Demonstrativo de Resultados da Avaliação Atuarial - DRAA será encaminhado ao Ministério da Previdência Social, até 31 de julho de cada exercício. 


\section{Do Plano de Benefícios}

O PREVBAND oferece os seguintes benefícios aos seus assegurados:

- Aposentadoria por invalidez;

- Aposentadoria compulsória;

- Aposentadoria por idade e tempo de contribuição;

- Aposentadoria por idade;

- Auxílio-doença, salário maternidade e salário-família.

Quanto aos Dependentes oferece pensão por morte e auxílio reclusão.

\section{Dados Funcionais Bandeira/MG - Dez/2015:}

Servidores ativos - 198; Servidores inativos (aposentados) - 39; Pensionistas -3 .

Dados Financeiros- Bandeira/MG - Dez/2015:

Receitas Financeiras em Dez/2015:

Contribuição Patronal (Prefeitura e Câmara): R\$ 601.702,76;

Contribuição de servidor ativo (Prefeitura e Câmara): R\$ 298.437,73;

Outras receitas - Aporte Déficit Atuarial: R\$ 175.407,74;

Parcelamento Contribuições atrasadas: $\mathrm{R} \$ 231.883,17$;

Total da Receita: 1.307.431,40

Despesas Previdenciárias em Dez/2015:

Despesa com inativo e pensionista: $\mathrm{R} \$ 645.785,38$

Despesa administrativa: $\mathrm{R} \$ 64.074,18$

Outras despesas:

Salário-família: R \$ 7.760,15;

Auxílio-doença: R \$ 43.467,85;

Salário-maternidade: $\mathrm{R} \$ 47.341,16$;

Total da Despesa: 808.428,71

RECEITA A DESPESA -RPPS DE BANDEIRA - DEZEMBRO/2015

\begin{tabular}{|l|l|l|l|}
\hline RECEITA/Percentual & TOTAL & DESPESA/Percentual & TOTAL \\
\hline Contribuição Patronal 46,02\% & $\mathrm{R} \$ 601.702,76$ & $\begin{array}{l}\text { Despesa com inativo e } \\
\text { pensionista79,88\% }\end{array}$ & $\mathrm{R} \$ 645.785,38$ \\
\hline Contribuição de servidor ativo22,82\% & $\mathrm{R} \$ 298.437,73$ & Despesa administrativa7,92\% & $\mathrm{R} \$ 64.074,18$ \\
\hline Aporte Déficit Atuarial 13,41\% & $\mathrm{R} \$ 175.407,74$ & $\begin{array}{l}\text { Outras despesas } \\
\mathbf{1 2 , 1 9 \%}\end{array}$ & $98.569,16$ \\
\hline $\begin{array}{l}\text { Parcelamento Contribuições atrasadas } \\
\mathbf{1 7 , 7 3 \%}\end{array}$ & $\mathrm{R} \$ 231.883,17$ & & - \\
\hline TOTAL & $\mathbf{1 . 3 0 7 . 4 3 1 , 4 0}$ & TOTAL & $\mathbf{8 0 8 . 4 2 8 , 7 1}$ \\
\hline $\begin{array}{l}\text { DIFERENÇA ENTRE } \\
\text { RECEITA/DESPESA }\end{array}$ & - & & $\mathbf{4 9 9 . 0 0 2 , 6 9}$ \\
\hline
\end{tabular}

ELABORAÇÃO PRÓPRIA - DADOS OBTIDOS PELAS INFORMAÇÕES DA GESTORA DO RPPS DO BANDEIRA- MG 
A análise realizada na pesquisa se desenvolve a partir de dados da receita e da despesa, obtidos conforme as informações enviadas pela gestora do RPPS do município de Bandeira.

Nota-se que a maior parte dos recursos arrecadados proveio da contribuição patronal, qual seja, $46,02 \%$ da receita do RPPS. A contribuição do servidor ativo representa um percentual de $22,82 \%$, enquanto que o aporte pelo déficit atuarial e o parcelamento das contribuições atrasadas, representa um percentual de $31,14 \%$. Desta forma, estas duas parcelas ,relacionadas às receitas e despesas, para que haja o equilíbrio financeiro e atuarial do RPPS do município precisam entrar no caixa como receita para o regime e sair como despesa para o Ente Federativo.

O Regime Próprio de Previdência Social do município de Bandeira, que apresenta resultado positivo, onde a receita auferida foi de ( $\mathrm{R} \$ 1.307 .431,40)$ e a despesa ocorrida de ( $\mathrm{R} \$ 808.428,71)$,daí o resultado de superávit obtido de ( $\mathrm{R} \$ 499.002,69)$. De um modo geral, vê-se que a situação financeira do RPPS do munícipio é favorável para a sustentabilidade, porém há que se esclarecer que análise financeira por si só não é suficiente para traçar o diagnóstico é necessário de uma análise geral com alcance de outras áreas.

\section{Perguntas e Respostas Sobre oInstituto Municipal - PREVBAND}

Abaixo constam as perguntas que foram elaboradas e enviadas à gestora do Instituto Municipal dePrevidência, no endereço virtual (prevband@ @otmail.com):

\section{1 - Como é feita a aplicação dos recursos do PREVBAND?}

Resposta: Aplicam em títulos públicos federais que são os fundos do IMAB e do IRFM-1.

Observa-se que aaplicação dos recursos previdenciários do Instituto Municipal - PREVBAND, foramfeitas em títulos público,(Fundos IMAB e IRFM-1). Importante destacar que esta aplicação é a maneira mais segura para a garantia futura dos assegurados.

\section{2- O PREVBAND tem o Certificado de Regularidade Previdenciária?}

\section{Resposta: $\underline{\operatorname{Sim}}$}

Nota-se que o PREVBAND está de acordo com as exigências legais aplicadas, sob o ponto de vista do Ministério da Previdência Social, que é o órgão responsável pela emissão do documento. O RPPS do município está cumprindo os critérios previstos na Lei ${ }^{\circ} 9.717 / 98$, que atesta que o ente federativo segue as normas de gestão, assegurando assim benefícios a curto aos seus seguradose ao longo prazo necessita de estudos e análise de outras áreas.

A emissão desse certificado para o município é de suma importância, pois confere a possibilidade do município de celebrar acordos, contratos, convênios, financiamentos, avais e 
subvenções, em geral, de órgãos ou entidades da Administração Direta e Indireta da União ou até para pagamento dos valores referentes à compensação previdenciária.

3 - O PREVBAND tem débitos parcelados?

Resposta: Sim.

4 - Mais de uma vez?

Resposta: Sim. Os débitos contraídos pelo PREVBAND foram decorrentes de valores não depositados pelo município, ao longo desses anos, quando já obrigatória a sua contrapartida financeira ao regime previdenciário. Atualmente, existemdois parcelamentos que são pagos pelo Ente, sendo um referente às contribuições previdenciárias atrasadas e o outro deum aporte para amortização dos déficits atuariais.

Observa-se queo pagamento desses parcelamentos, que seguem o rito legal, faz como que o RPPS do munícipio se equilibre tanto financeiramente e atuarialmente, tendocomo finalidade a garantia futura dos assegurados e da sustentabilidade do regime.

5 - Foi perguntado para gestora do RPPS se toda prestação de contas tem parecer atuarial?

Resposta: $\underline{\text { Sim. }}$.

Nota-se que, de acordo com a Lei ${ }^{\circ}$ 9.717/98, a gestão do RPPS é obrigada a fazer uma avaliação atuarial, inicial e em cada balanço, bem como auditoria, promovida por entidades independentes legalmente habilitadas. Significa dizer que o RPPS deve contar, pelo menos, com esses dois tipos de assessoria externa.

Em relação à avaliação atuarial, constatou-se que o RPPS do Bandeira vem cumprindo tal exigência e que o parecer atuarial é assinado por técnico habilitado.

\section{A Composição da Gestão do RPPS de Bandeira:}

- Gestor do Fundo: Maria Vitória de Carvalho Freitas;

- Conselho Fiscal: Evani Gomes da Silva, Laurita Barbosa da Silva, Otacílio Pereira e Ana Neta Pereira Rocha;

- Prefeito do município de Bandeira: Antônio Rodrigues dos Santos

Dessa análise, levando em consideração estas circunstâncias, para apurar a viabilidade do RPPS do município de Bandeira, concluímos que este regime está caminhando para a manutenção da sustentabilidade e também para assegurar a aposentadoria futura de seus servidores. 
Observamos que, no pequeno município, a implantação do Regime Próprio de Previdência Social pode se mostrar vantajosa, se este promover uma avalição atuarial criteriosa para organização do plano de custeio e do plano de benefício.

Conclui-se da análise que a gestão responsável é de fundamental importância para a manutenção do Regime Próprio de Previdência Social do Município de Bandeira.

\section{Marco Metodológico}

Trata-se de uma pesquisa exploratória, baseada na investigação documental, de natureza descritiva. O problema pesquisado é abordado de forma qualitativa, pois o estudo apresenta situações que não podem ser traduzidas em números. $\mathrm{O}$ estudo do caso acontece através de documentos bibliográficos, para serem analisados dentro das dimensões da pesquisa no modelo proposto.

Godoy, (1995,p. 58), explica algumas características principais de uma pesquisa qualitativa, o qual embasa também este trabalho: "considera o ambiente como fonte direta dos dados e o pesquisador como instrumento chave; a análise dos dados foi realizada de forma intuitiva e indutivamente pelo pesquisador, não requereu o uso de técnicas e métodos estatísticos; e, por fim teve como preocupação maior a interpretação de fenômenos e a atribuição de resultados.

De acordo com os dados da Secretaria de Previdência Social, existem 212 municípios no Estado de Minas Gerais que mantêm RPPS para seus servidores, ou seja, 24,83\% do total dos 853 municípios mineiros.

Para a coleta dos dados foram utilizados os instrumentos, principalmente a internet, mediante pesquisa na página institucional www.previdência.gov.br e no Portal da Transparência no sítio eletrônico do município de Bandeira,https://bandeira-mg.portaltp.com.br/módulos/geral/sobre.aspx, e também através do endereço eletrônico da unidade gestora_do instituto de previdência - PREVBAND, no endereço virtual do regime, (prevband@hotmail.com), onde foram coletados dados de vários relatórios.

\section{Análise dos Resultados}

Da análise, identificam-se os pontos considerados como vantagens para a sustentabilidade da manutenção do Regime Próprio de Previdência Social do Município de Bandeira com respeito a:

- Economia com as alíquotas, que podem variar entre $11 \%$ e $22 \%$, no máximo, de acordo com a avaliação atuarial realizada, anualmente. Enquanto que no RGPS as alíquotas de contribuição são fixas 
em $22 \%$ e aplicadas sobre a folha de pagamento. Isso significa uma economia possível de até $50 \%$ com encargos previdenciários, gerando, assim, uma economia ao erário público e sendo algo atrativo para manutenção e para o gestor do ente federado municipal;

- Na compensação financeira, implantada pelo RPPS, o município passa a ser credor do INSS, podendo realizar a compensação financeira previdenciária, buscando recursos do INSS e capitalizando cada vez mais seu RPPS, tendo em vista que os valores são recuperados em forma de compensação, possibilitado um equilíbrio financeiro e aumento na sustentabilidade para assegurar as aposentadorias dos servidores;

- As contribuições tanto do servidor como a patronal são controladas pela própria unidade gestora do RPPS e investidas no mercado financeiro através dos títulos públicos federais. Muitas prefeituras conseguem atrair novos bancos para abrir agências em seus municípios por conta dos recursos que seus RPPS têm para investir e movimentar. O que favorece a geração de empregos e a economia local.

- Da análise quanto à sustentabilidade para assegurar a aposentadoria dos servidores do Bandeira, foi observada a existência de uma maior transparência das contas públicas, através do Portal da Transparência do município de Bandeira, possibilitando uma maior facilidade de fiscalização. Ressalta-se assim a participação dos servidores nos Conselhos, auxiliando o Município na administração do Regime Próprio de Previdência Social, em conformidade com legislação; com ressalva na indicação do Gestor do Fundo Previdenciário, pelo chefe do Executivo, (Prefeito).

A pesquisa realizada para o tema, com certeza, não é capaz de oferecer um diagnóstico preciso do problema como o todo. Com os dados obtidos, observa-se que o Regime Próprio de Previdência Social do Município de Bandeira, por ser de pequeno porte, tem a sua sustentabilidade possível no curto prazo, desde que observe o equilíbrio financeiro. Caso não sejam tomadas medidas capazes de reduzir os déficits projetados com o parcelamento das contribuições previdenciárias atrasadas e o aporte para amortização dos déficits atuarial, prevê-se uma situação futura de insustentabilidade.

\section{Conclusões}

O tema de pesquisa do trabalho está relacionado à previdência social. No decorrer do estudo ficou evidenciado que os sistemas previdenciários do Brasil possuem características equivalentes entre si, também com a América Latina e com o resto do mundo. 
No princípio, o direito à previdência estava mais relacionado ao seguro social, destinado a uma categoria determinada, que era a dos servidores urbanos. Posteriormente expandiu-se até atingir toda população economicamente ativa.

A previdência social é um direito existente na Constituição Federal de 1988, a qual foi sendo aperfeiçoada através de emendas constitucionais. É um direito que está em constante evolução no Brasil e visa a alcançar os objetivos sociais, políticos e econômicos com dignidade para os segurados, de forma que o equilíbrio do sistema previdenciário passou a ser uma preocupação para o Governo.

Inicialmente, foi organizado em três regimes previdenciários: RGPS, RPPS e RPPC. Incluído um quarto regime em 2012, o RPCSP.

No Brasil, especialmente a partir da inclusão do capítulo da seguridade social, na Constituição Federal de 1988, e com a regulamentação dos RPPS, através da Lei no 9.717/1998, houve uma mudança significativa dos regimes e exigências relacionadas ao caráter contributivo e ao equilíbrio financeiro e atuarial dos regimes.

Não existe um marco temporal específico para a criação dos regimes próprios dentro dos entes federativos, mas, através do estudo, percebe-se que foi a partir da emenda constitucional n. 20/98que os entes passaram a adotar os regimes próprios de previdência com a ideia de dar independência e poder gerir os recursos no âmbito de cada ente, seja ele União, Estados e Municípios com a administração compartilhada com os seus servidores.

Em decorrência da pesquisa, entendemos ainda, que as emendas constitucionais n. 20/98 e n.41/03 foram responsáveis pela introdução de mudanças estruturais nos sistemas de previdência no país. A primeira com reformas significativas dando ênfase no caráter contributivo, na necessidade do equilíbrio financeiro e atuarial, modificando o sistema previdenciário com um novo modo de previdência social para servidores públicos. A segunda com mudanças trazidas, a qual indiscutivelmente trouxe maiores benefícios para os segurados, como também novas regras para o custeio e a concessão de benefícios, cabendo à administração a cobertura do regime em caso de déficit financeiro, constituindo num ato de moralização do orçamento dos regimes próprios de previdência social. Cito ainda, a Lei $\mathrm{n}^{\circ}$ 9.717/1998que estabeleceu normas gerais para a organização e o funcionamento dos regimes.

O panorama dos RPPS dos municípios mineiros também não difere dos outros municípios dos demais estados do Brasil que adotaram o modelo de proteção social, decorrente do trabalho e vinculado a uma contribuição mensal, tendo o valor de benefício proporcional à contribuição efetuada. Os beneficiários são os segurados e seus dependentes que terão direito às aposentadorias, pensões, auxílio doença, entre outros.

Ocorre que ao criarem os regimes próprios, os entes não se preocuparam com a manutenção do equilíbrio fiscal, financeiro e atuarial, e, hoje, isso vem sendo o maior desafio que se coloca para tornar os RPPS's com sustentabilidade garantida para assegurar a aposentadoria.

344 Id on Line Rev. Mult. Psic. V.12, N. 42, p. 322-348, 2018 - ISSN 1981-1179 Edição eletrônica em http://idonline.emnuvens.com.br/id 
O foco da pesquisa é sobre o regime próprio de previdência social, especialmente o municipal. O caso utilizado para pesquisa foi o município de Bandeira, cidade de pequeno porte, em que se percebeu que a sustentabilidade, no curto prazo, é possível. Da análise da diferença entre a receita e a despesa há equilíbrio financeiro. Porém, no longo prazo, para que esse equilíbrio permaneça, há a necessidade de acontecer um estudo de uma avaliação atuarial anual criteriosa, (com base nas características biométricas, demográficas e econômicas da população, cujo objetivo principal é estabelecer de forma adequada, os recursos necessários para garantia dos pagamentos dos benefícios previstos pelo regime),haja vista o aumento gradativo das despesas previdenciárias e do prolongamento da expectativa de vida da população. Desta forma, caso não sejam tomadas medidas capazes de reduzir os déficits projetados com o parcelamento das contribuições previdenciárias atrasadas e o aporte para amortização dos déficits atuariais, ainda mais diante da demora das reformas previdenciárias no país, a situação futura tornará insustentável, não só para o município de Bandeira, mas para todo Brasil.

A previdência social não deve a ser analisada somente a partir dos aspectos fiscal, financeiro e atuarial, mas também pela sua dimensão política, pois, no Brasil, é tratada como uma política pública e social. A participação da sociedade é de extrema importância, haja vista que o benefício previdenciário decorre de contribuições pelo segurado ao regime, ao longo de anos de trabalho. Por isso a necessidade de uma gestão responsável dos fundos previdenciários, independentemente da situação econômica vivida, atualmente, pelo país.

A reforma da previdência no Brasil na atualíssima conjuntura política e econômica representa um passo importante que terá de ser efetuado pela nova equipe de governo que precisam desenhar uma nova reforma do sistema previdenciário, pela necessidade de mudanças urgentes, situação que é inevitável, tendo em vista o crescimento da população e a idade média dos brasileiros com relação à expectativa de vida, sendo que o crescimento da despesa da previdência é insustentável no longo prazo. O Brasil é um dos países que ainda não fixou a regra da idade mínima para a aposentadoria, medida necessária para obter o equilíbrio fiscal nas contas, pois o orçamento previdenciário é o responsável pela maior despesa do atual governo federal.

Ao exposto, percebe-se que o RPPS do município de Bandeira tem, através da análise dos dados (receitas e despesas) apresentados pela entidade que gere o regime, a situação de sustentabilidade assegurada em curto prazo, mesmo que utilize de outros recursos para cobrir déficits previdenciários mensais do regime. Lembrando que esses recursos poderiam estar sendo utilizados em outras áreas do município como saúde, educação, segurança ou outras políticas públicas, gerando, assim, maior satisfação para sociedade e um desempenho fiscal maior para município. 


\section{Referências}

ARAÚJO, Fátima Fernandes; SANT'ANNA JÚNIOR, Alfredo. Sistemas municipais de previdência para servidores: um bom negócio para o município. Mas. In: O Município no século XXI: cenários e perspectivas. São Paulo: Fundação Prefeito Faria lima-CEPAM, 1999.

ALMEIDA, D.C. Responsabilidade Social: Um possível subsídio para aplicação dos Direitos Trabalhistas.3. ed. São Paulo LTR, 2012.

ALMEIDA, Artur Araújo, Análise da Viabilidade do Regime Próprio de Previdência Social do Município de Serra Branca. Campina Grande (UFCG), 2013..

ASSOCIAÇÃO DOS MEMBROS DOS TRIBUNAIS DE CONTAS DO BRASIL. Curso de aperfeiçoamento dos Servidores dos Tribunais de contas do Brasil. Gestão de Contas Públicas.

BERCOVICI, Gilberto. Constituição económica e desenvolvimento. Uma leitura a partir da constituição de 2988.São Paulo: Malheiros, 2005.

BUCCI, Maria Paula Dallari. Políticas públicas e Direito administrativo. Revista de informação Legislativa, Brasília, 1997, v. 34, n. 133, p. 89-98, jan. / mar.

BISPO, Helenílson Santos. O Desafio da Sustentabilidade dos Regimes Próprios de Previdência Social: Uma Análise A Partir da Situação de Oito Município Baianos, Tese em Administração, Universidade Federal da Bahia, Salvador, 2004.

BANDEIRA MUNICÍPIO DE MINAS GERAIS. Lei $\mathbf{N}^{\mathbf{0}}$ 277/2003, cria e instituí o Regime Próprio de Previdência Social dos Servidores do Município de Bandeira de Minas Gerais e dá outras providências.

BANDEIRA MUNICÍPIO DE MINAS GERAIS. Lei $\mathbf{N}^{\mathbf{0}}$ 332/2008, da Prefeitura Municipal de Bandeira, Dispõe sobre a criação da Autarquia Municipal, Denominada Instituto de Previdência Municipal de Bandeira - PREVBAND e dá outras providências. O Instituto de Previdência PREVBAND, respondidas pelo Gestor do Fundo, através do endereço virtual: prevband@ hotmail.com.

BRASIL. A Constituição Federal de 1988 do Brasil, chamada de Constituição Cidadã. Brasília: Senado 1988.

BRASIL. Lei $\mathbf{n}^{\mathbf{0}}$ 9.717.de 27 de novembro de 1998. Dispõe sobre regras gerais para a organização e o funcionamento dos Regimes Próprios de Previdência Social dos servidores públicos da União, dos Estados, do Distrito Federal e dos Municípios, dos Militares dos Estados e do Distrito Federal e dá outras providências.

BRASIL. Lei Complementar $\mathbf{n}^{\mathbf{0}} \mathbf{1 0 1}$ de 04 de maio de 2000.Lei de Responsabilidade Fiscal. Estabelece normas de finanças Públicas voltadas para a responsabilidade na gestão fiscal e dá outras providências.

BRASIL. A Emenda Constitucional $\mathbf{n}^{\circ}$ 20, de 1998, além de ratificar o regime contributivo, também tratou de dispor sobre os regimes de Previdência Federal de 1988 do Brasil.

BRASIL. A Emenda Constitucional $\mathbf{n}^{\circ} \mathbf{n}^{\circ}$ 41, de 2003, a qual indiscutivelmente trouxe maiores benefícios aos servidores públicos, Modifica os artigos 37,40,42,48,96,142,149 e 201 da 
Constituição Federal, e revoga dispositivos da Emenda Constitucional n 20, de 1998, e dá outras providências.

BRASIL. Lei $\mathbf{n}^{\mathbf{0}} \mathbf{. 1 0 . 8 8 7}$, de 18 de junho. Dispõe sobre a aplicação de disposições da Emenda Constitucional $n^{\circ} n^{\circ} 41 / 03$, e altera dispositivos da Lei $n^{\circ} 9.717 / 98$ e dão outras providências.

BRASIL. MPS- Ministério da Previdência Social / Secretaria de Políticas da Previdência Social/ Coordenação Geral de Normatização e Acompanhamento Legal/ disponível em www.previdência.gov.br, Atalho: Previdência no Serviço Público, Correio Eletrônico: spc.cgnal@previdencia.gov.br.

BRASIL. MPS- Ministério da Previdência Social / Secretaria de Políticas da Previdência Social / DRPSP - Departamento dos Regimes de Previdência no Serviço Público. Controle em Matéria Previdenciária: O Desafio da Construção da Sustentabilidade dos RPPS. Seminário TCE-MG "Direito Previdenciário: Fiscalização e Controle dos RPPS" Belo Horizonte/MG - 27/08/2014, disponível em www.previdencia.gov.br(Serviços aos RPPS - Previdência no Serviço no Serviço Público), drpsp@ previdencia.gov.br.

BRASIL. MPS- Ministério da Previdência Social / Secretaria de Políticas da Previdência Social / DRPSP - Departamento dos Regimes de Previdência no Serviço Público. Coordenação Geral de Normatização e Acompanhamento Legal. Coordenação de Normatização. Regimes Próprios de Previdência Social. Consolidação da Legislação Federal - Atualizada até Julho de 2015.

BRASIL. RPPS Brasil, Credenciada na CVM (Comissão de Valores Mobiliários). Consultoria especializada em Regimes Próprios de Previdência Social. Ferreira, Mauro André Branquinho, outubro de 2013.

BRASIL. MPS- Ministério da Previdência Social / Secretaria de Políticas da Previdência Social / DRPSP - Departamento dos Regimes de Previdência no Serviço Público -Regimes Próprios de Previdência Social - Consolidação da Legislação Federal - atualizada até 06/07/2015.

DIAS, Cícero Rafael. Tese de Fiscalização dos RPPS quanto à Sustentabilidade e Controle Atuarial - Departamento de Ciências Contábeis e Atuariais. Universidade Federal de Pernambuco, 2012.

FRANÇA, Álvaro Sólon de (1999). A previdência Social brasileira e a Economia dos Municípios. Brasília: ANFIF

LEITE, Celso Barroso. (1983.) Um Século de Previdência Social: balanço e perspectivas no Brasil e no mundo. Rio de Janeiro: Zahar Editores.

LOPES, Sylvio Pinto. (1983) Retrospecto, atualidade, medidas necessárias. In: LEITE, Celso Barroso. Um Século de Previdência Social: balanço e perspectivas no Brasil e no mundo. Rio de Janeiro: Zahar Editores, 1983.

MORAES, Marcelo Viana Estevão de. A Lei de Responsabilidade Fiscal e a Previdência dos Servidores Municipais. Brasília: Ministério da Previdência e Assistência Social, série estudos, vol. 2, 2001.

NOGUEIRA, Narlon Gutierres. O equilíbrio financeiro e atuarial dos RPPS: de princípio constitucional a política pública de Estado. Revista do Tribunal de Contas do Estado de Minas Gerais, outubro/novembro/dezembro 2011/ v.81- n.4- ano XXIX. 
OLIVEIRA, Jaime A. de Araújo; FLEURY TEIXEIRA, Sonia M. (IM) (1986) previdência social no Brasil: 60 anos de história da previdência social no Brasil. Petrópolis: Vozes.

SUSSEKING, Arnaldo Lopes. Previdência Social Brasileira. Rio de Janeiro., 1955

TAVARES, Marcelo Leonardo. Comentários à Reforma da Previdência- EC. N.41/2003. Rio de Janeiro, 2004.

MORAES, Marcelo Viana Estevão de . A Lei de Responsabilidade Fiscal e a Previdência dos Servidores Municipais. Brasília: Ministério da Previdência e Assistência Social, série estudos, vol. 2, 2001.

VELlOSO, Luiz Paranhos. Previdência Complementar. In: Leite, Celso Barroso. Um Século de Previdência Social: Balanço e Perspectivas no Brasil e no Mundo. Rio de Janeiro: Zahar Editores, 1983.

\section{Como citar este artigo (Formato ABNT):}

PRATES, Maria Aparecida Alves; BIANCHI, Graciela Fanego de. Análise da Sustentabilidade do Regime Próprio da Previdência Social para assegurar a Aposentadoria. Município de Bandeira Minas Gerais. Id on Line Rev.Mult. Psic., 2018, vol.12, n.42, p. 322-348. ISSN: 1981-1179.

Recebido: 23/08/2018;

Aceito: 13/09/2018 